DOI 10.37882/2500-3682.2020.05.03

\title{
ФАНТАСТИЧЕСКАЯ РЕАЛЬНОСТЬ ВИДЕОИГР В СОЦИОКУЛЬТУРНОЙ СРЕДЕ СОВРЕМЕННОГО МЕДИАЛАНДШАФТА
}

\section{VIDEO GAMES FICTION REALITY WITHIN THE SOCIOCULTURAL SPHERE OF THE CONTEMPORARY MEDIA LANDSCAPE}

A. Eliseev

Summary: The study conceptualizes the phenomenon of video games synthetic worlds' fiction reality in today's society media expanse. Among all the existing forms of interactive storytelling within the context of virtual culture video games are generally considered to be the most popular one. It was largely their intensive extending that almost all human activities and institutions went through so called mediation and gamification processes (both meaning the integration of interactive audio-visual elements in non-game experience for greater enhancement of user's attention). The statement that video games function not only as tools of societies' mediation but also as high value sociocultural artifacts has been put forward. The research focuses on bringing out the connections between digital games and virtual culture disseminated by mass media and mass communication, and also identifies the new interactive media impact on situations of interpersonal and external interaction, as well as on the modernization of social institutions. The generalized description of fiction reality and its sociocultural meanings incorporated in a technically constructed virtual space of video game has been presented. It had become apparent that video games have a diverse impact on a person, focusing on his psychology, interests and needs.

Keywords: fiction reality, virtual culture, physical reality, media landscape, video games, digitization, gamification, digital technologies, information society, online communication, multimedia,
$\mathrm{B}$ век информации и цифровых технологий социокультурная роль мультимедиа, представляющего собой комплекс различных видов сетевого контента, приобретает все большее значение. Современные средства массовой информации и массовой коммуникации дополнили процессы межличностного и внешнего взаимодействия, культурного выражения новыми инструментами, в результате чего человеку теперь стало доступно множество разных способов организации своего информационного жизненного пространства. В отличие от традиционных печатных материалов, содержащих типовые медиа-материалы, мультимедиа обладает сложной гибкой структурой, которая включает в себя не только текст, изображения, но и аудио, видео, компьютерную графику и анимацию, интерактивные программы, сенсорные игровые элементы - все в циф-

\author{
Елисеев Андрей Валерьевич \\ Аспирант, АНО ВО «Российский новый университет» \\ (Москва) \\ eliseev.andrey94@yandex.ru
}

Аннотация: В статье концептуализируется феномен фантастической реальности синтетических миров видеоигр в медиа пространстве информационного общества. Среди всех существующих на текущий момент форматов интерактивного повествования видеоигры общепризнанно считаются наиболее популярным в контексте современной виртуальной культуры. Во многом благодаря их интенсивному распространению почти все сферы жизнедеятельности человека подверглись так называемым процессам медиатизации и игрофикации - включению аудиовизуальных интерактивных элементов в неигровые ситуации и практики с целью усиления внимания пользователей. Выдвигается утверждение, что экранные игры функционируют не только как инструменты медиатизации общества, но и как ценные социокультурные артефакты. Статья фокусируется на выявлении связей между цифровыми играми и виртуальной культурой, распространяемой средствами массовой информации и массовой коммуникации, раскрывает характер воздействия новых интерактивных медиа на ситуации межличностного и внешнего взаимодействия, а также на процессы модернизации институтов социальной сферы. Автор представляет обобщенную характеристику фантастической реальности, заключенной в технически созданное виртуальное пространство видеоигры, и ее социокультурных значений. Сделан вывод, что видеоигры могут оказывать разностороннее влияние на человека, ориентируясь на его психологию, интересы и потребности.

Ключевые слова: фантастическая реальность, виртуальная культура, физическая реальность, медиаландшафт, видеоигры, цифровизация, игрофикация, цифровые технологии, информационное общество, онлайн-коммуникация, мультимедиа.

ровом формате. Во многом, благодаря им субъект достиг возможности использовать два канала общения одновременно и более, чтобы постоянно находиться в информационно-коммуникационном поле. В условиях интенсивной информатизации и медиатизации общества процессы коммуникации, творчества и познания получили импульс к модернизации благодаря социальным сетям, дополненной и виртуальной реальностям, и даже видеоиграм.

Игры всегда были и остаются неотъемлемой частью культуры. На протяжении веков они использовались не только для развлечения, но также для обучения полезным навыкам выживания, развития критического и стратегического мышления. С появлением экранных видеоигр академическое поле исследований этой те- 
матики вступило в активную фазу. Точно так же, как и в период повсеместного внедрения аналоговых радио и телевидения - первых медиа-феноменов, которые на текущий момент уже достаточно полно изучены, - сегодня в научной среде усиливается тенденция к увеличению числа работ, направленных на анализ цифровых игр. По словам М. Дж. Вульфа и Б. Перрона: «В последнее время видеоигры стали самой обсуждаемой и динамичной областью исследований в рамках новой теории медиа» [17, c. 1]. Их можно определить как парадигматическое выражение нового типа культуры - виртуальной.

Видеоигры являются частью глобальных медиатрансформаций, вызванных развитием современных цифровых технологий; новым продуктом виртуальной культуры, созданным в процессе гибридизации аудиовизуальных медиа форматов и мультимодальных интерактивных элементов, обеспечивающих гораздо более широкий диапазон взаимодействия по сравнению с традиционными жанрами, такими как кино или театр.

Актуальность настоящей статьи заключается в необходимости концептуализации феномена фантастической реальности видеоигр как гибридных медиатекстов - новой глобальной интерактивной системы, основанной на существующих социокультурных формах. Главная отличительная особенность экранных игр - интерактивность - запустила во многих сферах жизнедеятельности так называемый процесс игрофикации (о нем речь пойдет ниже), благодаря которому граница между фантастической реальностью, опосредованной передовыми цифровыми технологиями, и физическим миром с каждым днем становится все более прозрачной и вместе с тем, более обсуждаемой. Несмотря на это, видеоигры - сравнительно молодая область в науке, профиль которой все еще продолжает формироваться. Они представляются обманчиво простыми объектами для изучения, но на самом деле феномен видеоигр - многосложная проблема, требующая комплексного подхода. Всесторонний анализ этих интерактивных форм фантастической реальности может привести к новому пониманию социокультурной среды постоянно развивающегося медиаландшафта.

Фантастическая реальность синтетического мира экранной игры может быть использована в качестве инструмента для анализа механизмов взаимосвязи и интеграции игровых элементов в ткань социальной и культурной жизни. Тем не менее, большая часть исследований в этом направлении рассматривают категорию видеоигр в узкоспециальных значениях, например, с позиции образования и бизнес-технологий, о чем свидетельствуют многочисленные примеры учебно-педагогических $[4 ; 8 ; 10]$ и экономических работ $[5 ; 15 ; 18]$. Однако, по мнению Д. Руггелля и К. Макаллистера, природа видеоигр гораздо сложнее и конструируется на основе взаимосвязей между самыми разными отраслями научного знания, например: «...инженерией, математикой, герменевтикой, логикой, кинестезией, нарратологией, перформативностью, изобразительным искусством и многими другими областями» [14, с. 3], что говорит о ее многоаспектности и многоплановости. Сложную синтетическую природу этого феномена невозможно достаточно полно изучить в рамках отдельной научной дисциплины, теории или концепции, поскольку многие актуальные вопросы, связанные с ним, расположены на границе между культурой, философией, психологией, информационными технологиями и социальными науками в целом. Это утверждение обосновывает выбор автором в качестве основополагающего теоретико-методологического подхода к исследованию заявленной проблематики именно междисциплинарного синтеза культурологии, информационных и транс-медиа технологий, социологии, а также современного искусства.

Целью настоящей статьи является рассмотрение значения и функциональных особенностей фантастической реальности видеоигр в социокультурном пространстве оцифрованного информационного общества.

\section{Спешифика видеоигр в контекстах шифровизации, информатизашии и медиатизашии современного сочиума}

Самым большим изменением в медиа-ландшафте за последние двадцать лет стало не столько развитие сети Интернет, сколько усиление тенденции цифровизации отдельных направлений и объектов в культуре. Цифровые технологии дематериализуют медиатекст путем преобразования блоков данных из аналоговой в цифровую форму, что позволяет получать, обрабатывать и хранить значительно больший объем информации в сравнении с аналоговыми носителями. Кроме того, интерактивность новых медиа делает процессы взаимодействия между пользователями и поиск информации намного более доступными и удобными. Сегодня большинство медиатекстов (журналы, газеты и т.д.) передаются в цифровом формате. И даже традиционные бумажные книги сначала набирают на компьютере, а потом производят печать цифрового файла.

Цифровизация процессов коммуникации сделала обмен информацией более быстрым и эффективным, чем кто-либо мог предположить ранее. Тем не менее, ее влияние на культуру нельзя назвать всеобъемлющим. Несомненно, некоторые средства мультимедиа, такие как, например, видеоигры, являются абсолютно новыми (до возникновения цифровых технологий их не существовало), но здесь стоит подчеркнуть, что цифровизация культуры подразумевает под собой скорее переосмысление типовых форматов объектов культуры, а не полный отказ от них с последующей заменой на абсолютно новые. 
Об этом пишут М.Э. Рябова и И.В. Вашунина, - «Электронные средства массовой информации и современные визуальные медиа совершенно не обязательно дают нам принципиально новые формы общения. Нам остается и фотография, и картина, и кино, и театр, и просто живое общение» [2, с. 51]. Разница состоит лишь в том, что теперь практически любую информацию можно получить с помощью одного устройства - будь то персональный компьютер или смартфон с доступом к сети интернет.

Художественные произведения в книжных изданиях, музыка, записанная на пленку и фотографии в семейных альбомах - примеры старых медиа-материалов, которые сохранились в информационную эпоху, однако для этого им пришлось пройти процесс цифровизации. Теперь люди читают книги через специальные планшеты, слушают музыку, скачивая понравившиеся композиции на мобильный телефон, отправляют письма через электронную почту и т.д. Современный медиа-ландшафт меняется ускоренными темпами, благодаря чему виртуальная культура, как неотъемлемая часть информационного общества, начинает приобретать характеристики мультимодального, многосредового феномена. Новые социальные, экономические, образовательные и другие потребности требуют овладения новыми навыками, в том числе дивергентным мышлением. И один из ключевых способов, с помощью которого субъект не только формирует, но и познает новую культурную среду - это игры.

С целью избежать вопросов касаемо аппаратной платформы, на которой работают те или иные игры, в настоящем исследовании употребляется именно понятие «видеоигры», а не «компьютерные» игры. Поскольку предложенный термин применим ко всем типам современных цифровых игр: не только компьютерным, но и консольным, а также мобильным.

Видеоигру можно определить как семиотическую систему, пользователи которой вступают в искусственно созданный конфликт, строго ограниченный определенным набором правил. Аналогично ситуации в объективной действительности, управляемой физическими законами, в мире игры все объекты и инструментальные средства имеют четко определенную цель, и подчиняются своим порядкам. Именно поэтому обязательным условием правильного использования интерактивных элементов окружения является внимательное изучение игры и установленных разработчиками правил.

Видеоигры - яркий пример динамики современной культурной глобализации. По мере расширения занятого ими медиа-сегмента, игры начинают оказывать мощное влияние на разные сферы деятельности человека, благодаря чему, они все глубже интегрируются в систему культуры. Это один из популярных способов времяпре- провождения, рассчитанный на массовую аудиторию. Технический прогресс в области развития виртуальной культуры позволяет рассматривать их как высшую форму фантастической реальности.

Видеоигры одинаково влияют на психическое, эмоциональное, нравственное состояние личности, и на развитие общества в целом. Фантастическая реальность синтетических миров становится одним из определяющих факторов, трансформирующих современную цивилизацию из «общества потребления» в «общество участия», ведь в основе любой игровой концепции всегда лежит элемент воображения, который, согласно высказыванию К. Маркса, можно определить как, - «...великий дар, так много содействовавший развитию человечества». Понятие «физическая реальность» относится к любому явлению или объекту в окружающем мире объективной действительности, в пределах которого изначально существуют человек и общество, а любая другая реальность является особой синтетической надстройкой и поэтому называется фантастической.

Несмотря на распространенное утверждение, что основная функциональная особенность видеоигр связана с развлечением, компенсацией однообразности повседневности, они транслируют информацию, консолидирующую разные группы пользователей сети. Не стоит забывать и о том, что игры всегда были способом совместного времяпровождения, социальной активностью: начиная со времен изобретения нардов и шахмат, и до появления настольных игр (например, всемирно известной «Монополии»). Из этого следует, что современные видеоигры являются одной из быстрорастущих форм средств массовой информации и массовой коммуникации.

Такое восприятие видеоигр подкрепляется фактом, что человек новой информационной эпохи уже давно перестал быть пассивным получателем контента - теперь он также его производитель. Эта тенденция характеризуется способностью субъекта создавать пользовательский контент и размещать его в общедоступных источниках. Наглядный пример - фанатские субкультуры. Результаты исследований теоретиков культурологии и медиа-социологии А. МакКи и Г. Дженкинса подтверждают, что фанатские сообщества зачастую можно рассматривать не только как потребителей медиа-контента, но и как его активных неофициальных (а в некоторых случаях и официальных) производителей [12; 11].

Фан-культура, или фэндом - это сообщество, построенное вокруг феномена популярной культуры (книги, музыкальной группы, фильма, видеоигры и т. д.) объединяющее людей из разных народов, разных возрастных и социальных групп. Для участника этого общества фантастические миры служат источником вдохновения и фор- 
мой культурного самовыражения.

В фан-культурах творчество и художественное выражение проявляются, прежде всего, в жанрах фан-арта, фанфикшн и в косплее. Фанфикшн представляет собой истории, придуманные и написанные фанатами определенного художественного произведения; фан-арт можно определить как изображение, созданное поклонниками книги, комикса, фильма и т.д., основанное на мире произведения и его персонажах. Оно может быть разных стилей и направлений: традиционным портретным рисунком, концепт-артом или работой в жанре «цифровой рисунок»; косплей (сокращенный вариант английского термина costumed play, который можно перевести как «игра в костюмах») - это искусство изготовления костюмов, аксессуаров, фирменной атрибутики с целью изобразить героя из фантастического мира в реальной жизни.

Подобно другим традиционным формам, таким как телепрограммы, газеты, журналы, видеоигры все чаще используются для передачи той или иной информации. Они оказывают значимое влияние на культуру информационного общества, и тот факт, что общее число активных игроков непрерывно растет - тому прямое подтверждение.

Вопреки мнению некоторых исследователей, которые высказывались категорически против распространения видеоигр, (например, Ю. Провенцо заявил, что, - «Игры бессмысленны для большинства образовательных, социальных и культурных потребностей» [13, с. 34].) фантастическая реальность мира игры преобразует и усиливает межличностные связи. По утверждению Г. Кроуфорда: «Отсутствие подробного и всестороннего анализа важности видеоигр в повседневных моделях становится еще более поразительной, если учесть, что для растущего числа людей они являются относительно обычной, а порой даже обыденной деятельностью» [9, с. 148]. Цифровые игры стали точно такой же частью повседневной жизни, как книга, новостная телепередача или кино. Это объясняется тем, что человек информационной эпохи по-другому воспринимает видеоигры: устойчивое представление о виртуальных средах, как о продукте исключительно развлекательного характера, ушло в прошлое.

Видеоигры быстро становятся самой потребляемой и, следовательно, самой прибыльной культурной индустрией в мире. По данным исследования, проведенного аналитическим агентством NewZoo в 2018 году, в 28 странах мира насчитывается примерно 2,3 миллиарда игроков. Другими словами, примерно каждый четвертый регулярно играет в видеоигры. В прошлом году рынок игровой индустрии заработал около 137,9 миллиардов долларов [16]. Газета «Коммерсантъ» со ссылкой на ма- териал агентства NewZoo сообщает, что согласно прогнозам кампании, число игроков в России увеличится до 66 млн. человек до конца 2019 года [3]. Такой беспрецедентный успех видеоигр отразился и на других фундаментальных элементах медиаландшафта - музыке, кино и театре.

В эпоху цифровых технологий, чтобы не потерять актуальность и интерес зрителей, современные кинотеатры адаптируют и активно используют достижения технологического прогресса: очки виртуальной и дополненной реальностей, технологии 3D изображений, видеопроекции, светомузыку, игровые механики и пр. А недавно появился новый жанр интерактивного онлайнобщения на сцене, в основе которого лежат социальные сети.

В мае 2018 года на фестивале «Золотая маска» в номинации «Эксперимент» театр «Поиск» представил свой проект в жанре «спектакль-чат». Его главная особенность заключалась в том, что все задействованные в постановке актеры вели диалоги только в социальных сетях посредством мобильных устройств, причем у зрителей была возможность присоединиться к их беседам, и тоже стать частью сюжета. Однако и наблюдать за такой ситуацией невербальной онлайн-коммуникации, происходящей на сцене, тоже не менее интересно - ведь даже одна лишь переписка в чате может поведать удивительную историю.

Мобильные средства связи настолько прочно вошли в повседневную жизнь каждого человека, что представить дальнейшее существование без них достаточно сложно. И если несколько лет назад они обладали лишь одной функцией - коммуникационной - то теперь их список опций заметно расширился. Современные гаджеты не только обеспечивают функцию связи, но и служат хранилищем различных моментов жизнедеятельности, запечатленных на фотографиях и видеороликах. Для многих людей мобильный телефон стал своего рода ключом к социальной жизни, и, несомненно, игры - ее неотъемлемая часть.

Высокая популярность мобильных игр обусловлена в первую очередь их широкой доступностью - они не слишком требовательны к электронной начинке, в отличие от дорогих проектов с впечатляющей графикой, выпускаемых на консолях (Xbox One, PS4, Nintendo Switch и др.) и игровых ПК, благодаря чему они работают на большинстве современных устройств. Кроме того, в мобильные игры можно играть в дороге, во время перерыва на работе или в отпуске - достаточно иметь под рукой смартфон или планшет. Следует также добавить, что многие из них работает по принципу социально ориентированной платформы. 
Сегодня большая часть видеоигр, как правило, имеет высокоразвитую социальную игровую составляющую, независимо от того, играет ли пользователь в сессии с незнакомыми людьми, подобранными системой автоматического поиска или с друзьями, или просто сравнивает свои результаты в таблице лидеров. Взаимодействие субъекта с фантастической реальностью видеоигры и другими участниками, находящимися в ее среде, способно помочь разрешить ряд проблем социологического характера, среди которых особенно следует выделить формирование социокультурной картины мира личности и обновление института образования.

Это можно объяснить тем, что игра позволяет лучше понять социокультурную реальность. Она повышает уровень технической и медиа-грамотности, а также совершенствует навыки коллективной работы. М. Барр из университета Глазго в Шотландии полагает, что многопользовательские онлайн-видеоигры способствуют общему развитию уровня интеллекта, навыков общения у молодых людей, и кроме того, помогают им лучше адаптироваться к различным ситуациям социокультурного характера в реальной жизни [6, с. 86]. Здесь стоит добавить, что хотя многопользовательские интерактивные видеоигры и функционируют в качестве катализатора коммуникативного взаимодействия между игроками, анонимность, обеспечиваемая сетью интернет, при этом никуда не исчезает. Она по-прежнему дает человеку свободу выражать грани своей личности или экспериментировать с ними.

Как показывает практика, эффективность восприятия интерактивной, визуализированной информации на порядок выше, чем статичной односторонней, не предполагающей обратного отклика. Это обусловлено тем, что почти 70\% сенсорных рецепторов человека, обеспечивающих вход в нервную систему, расположены на сетчатке глаза (в среднем 120 миллионов рецепторов). Более того, примерно 50\% мозга выполняет функцию обработки именно визуальной информации. Человеку требуется 1/10 секунды, чтобы воспринять и понять визуальную ситуацию. Причем, о том, что визуализация информации облегчает процессы чувственного восприятия и познания еще в 1999 г. (фактически, это начало информационной эпохи) говорили С.К. Кард, Д.Д. МакКинлей и Б. Шнейдерман [7].

Для современного человека особое значение имеет форма подачи информации - она должна активизировать разум и чувства, вызывать эмоциональный отклик. Интерактивные фантастические миры видеоигр предоставляют новые возможности для более глубокого изучения процессов использования визуализированной информации с целью решения ряда практических задач. Например, проблем глобализации, социализации, инкультурации и формирования мультикультурной личности.
Многопользовательские онлайн-игры поощряют коммуникацию между участниками. Процесс внутриигровой социализации нередко приводит к формированию длительных отношений между игроками (в том числе и в реальной жизни). Цифровые технологии позволяют людям, которые никогда не встречались, легко преодолеть географические и языковые барьеры, и общаться посредством языка игр.

Любая активность пользователя в пределах границ фантастического мира видеоигры, по сути, носит характер гибридной культурной практики, которая нередко предполагает межкультурные контакты. Растущее международное значение игр обусловлено процессами глобализации и цифровизации, поскольку круг общения человека информационной эпохи больше не ограничивается отдельными социальными группами, составляющими его повседневное окружение. Играя, субъект регулярно взаимодействует с другими людьми по всему миру, тем самым развивая свою мультикультурную личность.

С эпистемологической точки зрения виртуальная культура дает представление о том, как видеоигры могут помочь проанализировать ряд аспектов социальной жизни в информационной эпохе. Важно подчеркнуть, что видеоигры не только способны экспонировать проблемы социального характера, но еще и формировать их, и способствовать трансформации уже существующих.

\section{Феномен игрофикашии сошиокультурного пространства современности}

В настоящее время в разных областях социальной реальности (бизнес, экономика, кино и т.д.) идет интенсивный процесс игрофикации - внедрение в общую рабочую концепцию той или иной сферы деятельности игровых механик. Это могут быть квесты, ролевые игры, системы очков, достижения, а также отсылки на популярные культурные феномены. Хотя игрофикация все еще находится на стадии становления, это направление развивается очень быстро.

В видеоиграх всевозможные значки и достижения служат наградой за выполнение второстепенных целей и задач, которые не влияют на результат игры, но привносят элемент разнообразия в исследование фантастического мира. Независимо от жанра видеоигры, достижения являются конвенциональным инструментом для мотивации пользователей продолжать играть и развивать свои навыки дальше.

Нечто подобное уже внедряют в операционные системы мобильных телефонов. Зачастую разработчики приложений и интернет сервисов добавляют в про- 
граммное обеспечение мобильных устройств значки и мини-задания, которые вместе составляют интуитивно понятный интерфейс. Так, с помощью достижений, баллов, интерактивных элементов и списков рейтингов крупные кампании-производители содействуют формированию новых компетенций у пользователей сети. Как правило, это делается для продвижения продаж и большего охвата аудитории.

Еще один пример: водители такси, зарегистрированные в онлайн-сервисе "Uber" зарабатывают поощрительные значки в специальном приложении. Так, значки «отличный сервис» и «приятная беседа» на первый взгляд могут показаться несущественной мелочью, но они обладают определенной функцией - побуждают водителей работать эффективнее. Здесь важно подчеркнуть, что игрофикация строится в том числе и на мотивационных психологических приемах, таких как самоутверждение и конкуренция. Играя, люди обычно используют разные умения и навыки, тем самым испытывая свою компетентность. При достижении условного результата они получают положительные эмоции, что вполне характерно для мотивированного человеческого поведения.

Существуют, в том числе, специализированные цифровые программы, задача которых заключается в концентрации внимания пользователя. Так, список лучших приложений Google play в 2018 году пополнила разработанная для мобильных устройств программа под названием "ForestApp". Она помогает пользователю не отвлекаться на смартфон или планшет, когда ему необходимо сосредоточиться на конкретной деятельности. Принцип работы этого приложения очень прост: каждый раз, когда субъекту нужно сосредоточиться на какой-либо активности, он включает программу на своем телефоне и «сажает» виртуальное дерево. Пока приложение активно (оно блокирует доступ к другим функциям устройства), и человек не трогает телефон в течение установленного срока - дерево растет. Но стоит закрыть приложение - дерево погибает [1].

Таким образом, оставаясь сосредоточенным на протяжении длительного периода времени, программа поможет вырастить целый цифровой лес. В настоящий момент разработчики тестируют функцию получения виртуальной валюты через это приложение, которую можно использовать для покупки настоящей древесины.

Успешное взаимодействие с интерактивными элементами способно вызвать у субъекта ни с чем несравнимое чувство самоопределения, чувство выполненного долга (как и при завершении очередного уровня головоломки), но, что главное - ставит перед ним конкретную, заветную цель.

Сложные динамичные игры предлагают множество познавательных паззлов, за выполнение которых полагается цифровая награда. Ее получение определенно повысит уровень самооценки, и, несмотря на виртуальность приза, человек испытает настоящий эмоциональный подъем, поскольку успешное прохождение таких игр действительно требует сосредоточенного пространственного внимания и применения ряда других когнитивных навыков: памяти, многозадачности, умственной гибкости и т.д.

Одна из главных особенностей видеоигр заключается в силе эффекта погружения. Находясь в фантастической реальности виртуального мира, сознание человека входит в иммерсивное состояние. Иммерсивное состояние сознания - это психологический феномен, характеризующийся предельной сосредоточенностью на задачах, предусмотренных игровой ситуацией, чувством удовлетворения от их выполнения. Видеоигра вовлекает пользователя в процесс динамического взаимодействия с фантастической реальностью уже на этапе своего запуска, когда предлагает изучить электронный интерфейс и механику управления, а также установленный свод правил. Сам по себе игровой процесс, из-за вызываемого им довольно сильного иммерсивного состояния, нередко приводит к потере чувства времени и места. Несмотря на то, что временная потеря самосознания очевидна в ходе потребления любого традиционного медиа (например, когда субъект смотрит кинофильм или читает книгу), погружение в фантастическую реальность мира видеоигры имеет несколько иной порядок. Во многом это происходит благодаря усиленному эффекту присутствия, который возникает в результате тесного умственного, эмоционального и тактильного взаимодействия индивида с игровым миром и устройствами ввода-вывода информации. Необходимость выполнять сложные комбинации действий, изложенных выше - овладение системами управления, изучение механик игрового процесса, решение головоломок, стратегическое планирование и т.д. приводит к интенсивной концентрации. Игры специально создают неожиданные и удивительные ситуации, требующие от пользователя оригинального, творческого подхода, так же как и реальный мир, изобилующий запутанными сценариями с непредвиденными последствиями и непредсказуемыми результатами.

Фантастическая реальность видеоигры предоставляет человеческому мозгу пространство для безопасного исследования всего спектра сложностей объективной действительности. В качестве примера можно привести тренировочные авиасимуляторы, не так давно ставшие частью подготовки операторов беспилотных летательных аппаратов (БПЛА). Широкое использование дронов в военных и гражданских целях создало высокий спрос на квалифицированных пилотов такого типа машин. Цифровые системы обучения позволяют сделать профессиональную летную подготовку более доступной в 
условиях сокращения бюджета.

Симуляторы полета знакомят будущих пилотов с реальной кабиной самолета, оснащением боевого истребителя, или с устройством беспилотника; экономят топливо, а также полностью исключают износ двигателей летательных аппаратов. Кроме того, они могут воспроизводить экстремальные условия, моделировать чрезвычайные ситуации и сбои системы, не подвергая при этом опасности реальных людей. Полноценные авиасимуляторы используют передовые технологии в областях аэродинамики, компьютерной графики, коммуникации и воздушного движения.

Благодаря широкому диапазону игровых задач и проблем, которые можно решать методом проб и ошибок, современный человек учится смотреть на ситуации в реальной жизни с разных сторон. Цифровые технологии позволяют ему проживать в буквальном смысле сразу несколько отличающихся друг от друга жизней, и поэтому, можно предположить, что фантастическая реальность в любом случае всегда будет пересекаться с реальностью физической.

Конечно, вышесказанное еще не означает, что стоит целый день сидеть перед экраном монитора. Чтение книг, просмотр кинофильмов, занятия спортом - все это важная составляющая здорового образа жизни. Тем не менее, игровая индустрия, несомненно, будет играть еще большую роль в будущем, поскольку виртуальная культура продолжает расти и развиваться, обеспечивая новой средой для реализации творческих способностей. Видеоигры, как и все игры в целом, основываются на многих аспектах культуры, и, кроме того, выполняют роль связующего компонента между ними.

\section{$* * *$}

Фантастическая реальность видеоигры - это ориентированный на игрока процесс интерактивного повествования, который фокусируется на психологии каждого конкретного пользователя, его потребностях, интересах. Деятельность в пределах виртуального мира видеоигры имеет очевидное сходство с таковой в объективной действительности. Многопользовательские игры способны трансформировать идеи и мысли игроков, формировать у них новую социокультурную картину мира. Они предлагают свою собственную интерпретацию различных вопросов, в том числе и ряда проблем экзистенциального характера. К примеру, старый конфликт между добром и злом, нередко встречающийся в разных культурных формах на протяжении всей истории человечества (в мифологии, литературе, поэзии, кино и т. д.), получил новое отражение в виртуальном пространстве. Неудивительно, что философские темы попали в игровую среду, ведь за последние несколько лет цифро- вые игры достигли высочайшего уровня сложности проработки мира и глубины повествования. Их потенциал еще только предстоит раскрыть. Взаимодействие с фантастической реальностью стало неизбежным для всех, кто живет в информационном обществе. Дальнейшие исследования по целому ряду дисциплин необходимы, поскольку в последнее время реальные действия все чаще заменяются виртуальными.

Путешествия в фантастические игровые миры удовлетворяют несколько разных типов потребностей человека. Во-первых, потребность в ощущении собственной компетентности, т.е. желании получить контроль над определенной ситуацией. Людям нравится отслеживать свой внутриигровой прогресс, делиться успехами в получении электронных достижений с друзьями и со всем миром. Во-вторых, необходимость чувствовать себя полезным. Субъект испытывает положительные эмоции, когда ощущает значимость для других, поскольку своими действиями в фантастической реальности он вносит существенный вклад в развитие общества (пусть и виртуального). Можно предположить, что именно по этой причине многие игровые задания - так называемые квесты - зачастую строятся по принципу: помоги конкретному НИП (Неигровой персонаж. Герой, которым управляет не игрок, а искусственный интеллект) найти какой-либо предмет или спаси его от врагов.

Разумеется, все вышеперечисленные потребности могут удовлетворить работа, учеба, любимое хобби или занятия спортом. Но, очевидно видеоигры предлагают гораздо более интересный и эффективный способ. Они ставят перед пользователем увлекательные цели и наглядно демонстрируют прогресс в их достижении. Подобная система показала себя настолько хорошо, что ее уже можно встретить в социальных сетях, мессенджерах и на популярных интернет-порталах.

Начиная с момента своего появления в обществе, и до настоящего времени видеоигры одновременно восхищают, и вызывают тревогу. Например, некоторые исследователи, как было отмечено выше, убеждены в том, что они оказывают лишь негативное влияние на общее психологическое состояние человека. Однако не стоит забывать, что похожая реакция наблюдалась во время распространения книгопечатания и изобретения телевидения.

Сегодня видеоигры стимулируют рост мировой экономики, их внедряют в сферы образования, коммуникаций и в военный сектор. В них играет огромное число людей независимо от возраста, религиозных мировоззрений или национальной принадлежности. Фактически, для многих игры стали специфическим образом жизни. 
На мой взгляд, растущая популярность видеоигр может быть связана с их специфической способностью сочетать в себе современные виртуальные технологии, обеспечивающие высокую степень реалистичности изображения, и фантастическую реальность, основанную на динамичном повествовании и социокультурных маркерах. По аналогии с объективной действительностью, в них заложены свои правила и законы, история, география, нередко даже язык и аутентичная мифология. Сюжетные линии экранных игр часто соотносятся с морально-нравственными установками, ритуалами и ценностями, предоставляя игрокам доступ к универсальным знаниям, связанным с историей, обществом, человеком и культурой. Благодаря трехмерному моделированию, системе захвата движений и сложным программным модулям эти многоэлементные, визуально привлекательные синтетические среды кажутся крайне убедительными. Вероятно, по этой причине они и стали основными медиапродуктами и широко популярными артефактами современной виртуальной культуры.

\section{ЛИТЕРАТУРА}

1. Мобильное приложение Forestapp [Электронный ресурc] URL: https://www.forestapp.cc/ (дата обращения: 23.06.2019).

2. Рябова, М.Э., Вашунина, И.В. Функционирование зрительных образов в средствах массовой коммуникации // Вестник российского нового университета, сер.: «Человек в современном мире». 2016. №2. С. 50-54.

3. Шестоперов, Д. «Гейм-парад. Расходы россиян на видеоигры растут» [Электронный ресурс] Газета Коммерсантъ // URL: https://www.kommersant.ru/ doc/4019540 (дата обращения: 22.07.2019).

4. Ahmad, S.M.S., Fauzi, N.F.M., Hashim, A.A., Zainon, W.M.N. W. (2013). A study on the effectiveness of computer games in teaching and learning. International Journal of Advanced Studies in Computers, Science and Engineering. Vol. 2 (1).

5. Aleem, S., Capretz L.F., Ahmed F. (2016). Empirical investigation of key business factors for digital game performance, Entertainment Computing. Vol. 13. pp. 25-36.

6. Barr, M. (2017). "Video games can develop graduate skills in higher education students: A randomised trial." Computers \& Education. Vol. 113. pp. 86-97.

7. Card, S.K., Mackinlay, J.D., and Shneiderman, B. (1999). "Readings in Information Visualization: Using Vision to Think." Morgan-Kaufmann. San Francisco, CA. P. 712.

8. Chiang, Y.T., Lin, S.S.J., Cheng, C.Y., \& Liu, E.Z.F. (2011). Exploring online game players' flow experiences and positive affect. The Turkish Online Journal of Educational Technology. Vol. 10. No. 1.pp. 106-114.

9. Crawford, G. (2012). Video Gamers. Routledge, New York. P. 190.

10. Crocco, F., Offenholley, K., Hernandez, C. (2016). A proof-of-concept study of game-based learning in higher education. Simulation \& Gaming. Vol. 47 (4). pp. 403-422.

11. Jenkins, H. (1992). Textual Poachers: Television Fans and Participatory Culture. Routledge, New York and London. P. 352.

12. McKee, A. (2002). Fandom. In: Miller, T. (Ed.), Television Studies. BFI Publishing, London. pp. 66-70.

13. Provenzo, E. (1991). Video Kids - Making Sense of Nintendo. Harvard University Press, Massachusetts. P. 184.

14. Ruggill, J.E., McAllister, K.S. (2011). Gaming Matters: Art, Science, Magic, and the Computer Game Medium. Tuscaloosa, AL: University of Alabama Press. P. 168.

15. Wesely, D., Barczak, G. (2010). Innovation and Marketing in the Video Game Industry. London: Routledge. P. 280

16. Wijman, T. (2018). Newzoo's 2018 Report: Insights Into the $\$ 137.9$ Billion Global Games Market [Электронный ресурc] Newzoo // URL: https://newzo0.com/ insights/articles/newzoos-2018-report-insights-into-the-137-9-billion-global-games-market/ (дата обращения: 24.07.2019).

17. Wolf, M.J.P., Perron, B. (2003). The Video Game Theory Reader. London; New York: Routledge. P. 368.

18. Zackariasson, P., Wilson, T.L. eds. (2012). The Video Game Industry: Formation, Present State, and Future. New York: Routledge. P. 282.

с Елисеев Андрей Валерьевич (eliseev.andrey94@yandex.ru). 